\title{
Ontología estética, estética ontológica: un replanteamiento del arte y lo bello desde el realismo especulativo
}

\section{Aesthetic ontology, ontological aesthetic: a rethinking of art and beauty from speculative realism}

\author{
Mario Teodoro Ramírez \\ Universidad Michoacana de San Nicolás de Hidalgo, México \\ marioteo56@yahoo.com.mx
}

Resumen: En este artículo se cuestiona si el arte, y el objeto estético en general (lo bello), puede ser pensado desde la perspectiva de la nueva corriente filosófica del realismo especulativo. El asunto es enfocado bajo una doble perspectiva: lo que sería una concepción ontológica de lo estética y lo que sería una concepción estética de la ontología. Sólo bajo este doble enfoque es posible responder al desafío que lo estético plantea al pensamiento ontológico en general.

Palabras clave: bello, ontología, estética, realismo especulativo, Meillassoux.

Abstract: In this article, it is questioned whether art, and the aesthetic object in general (the beautiful), can be thought from the perspective of the new philosophical current of speculative realism. The subject is approached from a double perspective: what would be an ontological conception of aesthetics and what would be an aesthetic conception of 
ontology. Only under this double approach is it possible to respond to the challenge that the aesthetic poses to ontological thinking in general.

Keywords: Beautiful, Ontology, Aesthetics, Speculative realism, Meillassoux.

Recibido: 23 de julio de 2018

Aceptado: 27 de febrero 2019 http://dx.doi.org/10.15174/rv.v0i24.418

U

na de las objeciones que se pueden hacer al realismo especulativo -la corriente de pensamiento que ha irrumpido recientemente en la escena filosófica abogando por una primacía de lo real más allá de todo subjetivismo, idealismo o correlacionismo, esto es, más allá de todo antropocentrismo- ${ }^{1}$ es por el lado de la estética, del arte y de lo bello. ¿Puede existir lo bello sin un sujeto que lo aprehenda, que lo defina, que, de alguna manera, lo haga existir? ¿Algo puede ser bello sin alguien que lo vea? ¿Hay arte sin seres humanos? Desde estos cuestionamientos, el arte y lo bello son asumidos como el colmo del carácter indeclinablemente subjetivo y antropocéntrico de nuestra experiencia de lo real y de lo real mismo; es decir, como argumento último contra cualquier pretensión de restablecer el realismo como perspectiva filosófica general. Pero, ¿̇no es acaso la concepción subjetiva de lo bello producto de un acendrado modo de pensar, de una episteme históricamente configurada que nos hace creer que no podemos pensar ni ver más allá de sus supuestos y de su régimen de operación? Se trata de lo

${ }^{1}$ El término "correlacionismo", introducido por Quentin Meillassoux, caracteriza a todo el pensamiento moderno, en cuanto postula como condición y límite de la filosofía la correlación sujeto-objeto, lenguaje-mundo, ya en las filosofías de corte analítico o ya en las de corte fenomenológico-hermenéutico. Cf. Meillassoux, 2015: 29. Para un enfoque general de esta corriente filosófica, ver: Ramírez, 2016. 
que podemos llamar, desde el punto de vista estético, la episteme general de la modernidad, y es lo que, en principio, habría que cuestionar para dar lugar a la pregunta por la posibilidad de una nueva concepción de lo bello y, más concretamente, de una concepción ontológica, o por lo menos un poco más objetiva y menos palmariamente subjetiva y antropocéntrica de lo que ha sido hasta hoy.

Podemos encontrar ejemplos de una concepción ontológica de lo bello no sólo en los tiempos posmodernos, sino en muchos momentos del pensamiento premoderno, en la antigüedad clásica y en el medievo. También podemos hallarlos, auxiliados por la historia y los estudios antropológicos, en las modalidades estéticas y artísticas, a veces vistas como meramente exóticas, de culturas no occidentales (como el arte azteca: la Coatlicue es ejemplo por excelencia de una obra nada correlacionista o antropocéntrica). El interés de la pregunta por una concepción ontológica de lo bello no es, pues, ocioso o superfluo. Tiene o puede tener un amplio rango de implicaciones tanto en el campo del pensamiento como en el campo socio-cultural y humano en general. Ante todo, debemos comprender que una visión ontológica de lo bello debe ajustar cuentas con toda concepción meramente -reductivamente- psicológica, sociológica, histórica o antropológica de la experiencia estética. En lugar de conformarse simplemente con negar tales perspectivas -la perspectiva humanista en general-, una ontología de lo bello propondría redefinirlas para reformular desde fundamentos últimos, no relativistas, sus condiciones y límites de validez. A su vez, y de forma complementaria, una perspectiva estética de la ontología nos permitirá elevar al plano filosófico, al plano del pensamiento, el significado y alcance del arte y de lo bello.

Así, este ensayo trata de las relaciones e interrelaciones entre Estética y Ontología, en su doble movimiento. Por una parte, hablamos de ontología estética, es decir, del significado de una concepción del Ser-del ente, de lo existente-que sigue el modelo -como 
caso paradigmático- del arte y de lo bello. Por otra parte, hablamos de estética ontológica para explorar una forma de experiencia estética y de quehacer artístico, en particular el contemporáneo, cuya función y sentido último remite a una aprehensión del ser en cuanto ser, esto es, a una comprensión ontológica. En verdad, esta función ontológica sería una característica de todo arte, al igual que una concepción estética de la ontología no haría sino revelar el sentido último de toda ontología. Éstas vendrían a ser las apuestas especulativas de nuestra indagación.

De esta manera, proponemos criticar la concepción subjetivoantropológica de lo bello y definir el sentido de una concepción ontológica de la belleza $-\mathrm{y}$, a la vez, de una concepción estética de la ontología- desde la perspectiva de la filosofía del realismo especulativo. Para el primer punto discutimos el carácter de la estética kantiana, considerada en términos generales como el momento fundacional del subjetivismo estético moderno. Comentamos, en el apartado inicial, la crítica de Gadamer al kantismo para exponer de inmediato, en el segundo apartado, la reintepretación que algunos pensadores neorrealistas, como Shaviro y Harman, han hecho de la concepción kantiana del arte y lo bello y, en general, del sentido de la estética. En esta línea exponemos, en un tercer apartado, una interpretación estética del "principio de irrazón" presentado por Quentin Meillassoux. En un cuarto apartado, y a modo de conclusión, hablaremos del significado filosófico del arte y de las tareas de una estética ontológica.

\section{Estética subjetiva}

Aunque la concepción subjetiva del arte y lo bello comenzó a fraguarse desde el Renacimiento, es en el pensamiento del siglo XviII 
-empirismo clásico, Ilustración- ${ }^{2}$ que alcanza su definición plena. En general, se asume que Kant defiende una concepción subjetiva de lo bello y que es él quien establece las bases del subjetivismo estético de la modernidad en general (lo bello es algo puramente subjetivo y el gusto es puramente relativo). ¿Pero qué tan cierta es esta interpretación? Comentaremos la que tal vez sea la crítica más acabada del subjetivismo kantiano, que es la presentada por HansGeorg Gadamer, el fundador de la corriente hermenéutica de la filosofía contemporánea. Como alternativa, de la mano de Steven Shaviro, presentaremos a través de una cierta crítica a Gadamer, una re-lectura ontológica de Kant y sus consecuencias para la interpretación estética del nuevo realismo o realismo especulativo.

Aun siendo el pensador meticuloso que es, Gadamer se hizo eco, quizá de forma apresurada, de la interpretación del kantismo como un mero subjetivismo estético. La destrucción de la concepción subjetiva de lo bello es a tal grado relevante para los propósitos de la hermenéutica gadameriana que se convierte en el alfa y omega de Verdad y método, su principal obra (Gadamer, 1977). Aparece al inicio del libro como la condición para una fundamentación de una hermenéutica capaz de rebasar los límites de todo subjetivismo: la comprensión no es un acto de la subjetividad, ni siquiera de la intersubjetividad -una trama de sujetos-: es un acto del lenguaje, un movimiento de la experiencia que pone en juego diversos aspectos de la condición humana-historicidad, tradición, consenso, diálogo-. También, aparece al final de la obra ("El aspecto universal de la hermenéutica”) como base y condición para la universalización de la hermenéutica y para el arribo a lo que el filósofo alemán llama una "ontología hermenéutica". Gadamer está en contra de la estética subjetiva porque está en contra, en general,

${ }^{2}$ Para un visión sintética del pensamiento estético de la Ilustración confrontar Cassirer (1972: 304 y ss). 
de la eliminación de todo carácter cognoscitivo del arte, esto es, la eliminación de la cuestión de la verdad en la experiencia estética. Según él, esta eliminación es el complemento y la confirmación del objetivismo científico moderno, para el cual la verdad es privativa del conocimiento metódico de las ciencias empírico-naturales al que deberán someterse las humanidades, las ciencias del espíritu (ciencias humanas, ciencias sociales, ciencias de la cultura, etc.) si es que pretenden validez y verdad. Como sabemos, Gadamer y toda la línea fenomenológico-hermenéutica de la filosofía del siglo $\mathrm{xx}$, considera que esa es una vía errada y de consecuencias funestas para la comprensión de lo humano.

Todos los conceptos de la estética kantiana son cuestionados puntualmente por Gadamer en la primera sección de Verdad y método ("Elucidación de la cuestión de la verdad desde la experiencia del arte"): el carácter subjetivo de lo bello, el desinterés estético -carácter no cognitivo ni moral de la experiencia estética-, la forma reflexionante -no determinante- del juicio del gusto, el sentido común estético como a priori del juicio del gusto, la noción del genio como libertad, etc. En contra, Gadamer concibe a lo bello como una experiencia de conocimiento bajo una perspectiva que revalora todos aquellos elementos de la formación humana que la modernidad ilustrada cuestionó y despreció: la fuerza de la tradición, el gusto como experiencia de integración social, el significado de la alegoría, el adorno, el sentido común en general, el valor del prejuicio y la pre-comprensión, etcétera, todo lo cual remite a la recuperación de una función de la "verdad" ligada a la experiencia humana en un sentido integral, es decir, en contra de su reducción a un aspecto parcial de nuestra condición -ya sea la experiencia metódico-objetiva del saber científico, ya sea su mera subjetivación psicologista o trascendental-. Gadamer propone como alternativa una concepción de lo bello como cualidad ontológico-hermenéutica: la cualidad de lo que aparece, de lo que 
se manifiesta: "en la esencia de lo bello está el que se manifieste" (Gadamer, 1977: 574), dice. La representación -la imagen- estética no es una reproducción o una copia sino una "presentación" de la cosa misma (Cf. Gadamer, 1977: 182 y ss). El ser de la cosa sólo se revela (Heidegger, 1956) en la obra de arte. Todo el punto hermenéutico-gadameriano estriba, así, en que no hay distinción (la "no-distinción estética") entre la manifestación -el aparecer-y lo que se manifiesta -el ser-, entre la cosa aprehendida y el sujeto que la aprehende. Por esto, para él, como para Heidegger, el arte es revelación de la verdad del ente y el lenguaje es manifestación del Ser mismo; según la famosa fórmula gadameriana, "el ser que puede ser comprendido es lenguaje” (Gadamer, 1977: 567). Lo bello como aparecer, y el arte como experiencia de transformaciónconstrucción de ese aparecer, es el modelo de la verdad para el lenguaje, la hermenéutica y las ciencias humanas en su conjunto.

No obstante, consideramos que la alternativa al subjetivismo estético que la filosofía gadameriana ofrece no escapa al correlacionismo (sujeto-objeto, humano-mundo) criticado por el nuevo realismo; al contrario, representa su versión más acabada -lo que Meillassoux llama "correlacionismo fuerte"- (Meillassoux, 2015: 63). Para la hermenéutica, no hay Ser fuera de la aparición o manifestación; de hecho, el Ser queda abducido de forma total en la manifestación -y en el lenguaje-. Esto termina sonando a un subjetivismo no del individuo sino de la especie: el humano y su lenguaje es todo lo que existe. Todo decir sobre el ser $-\mathrm{y}$ del serencuentra su condición y su verdad - del "decir" y del "ser"- en el lenguaje. Si queremos comprender al Ser lo que tenemos que comprender es el acto lingüístico de la comprensión y nada más. El Ser se desvanece ante la palabra como un fantasma se desvanece con las luces del amanecer. Este desvanecimiento del Ser, del Ser en cuanto tal, de la realidad más allá de nosotros, es el resultado final e ineludible de la ontología fenomenológico-hermenéutica en 
cuanto ontología que sólo ha podido plantearse desde la posición incuestionada de la "condición humana". En cuanto ontología del ser del ser humano ha resultado altamente valiosa, pero nos quedó a deber una ontología del Ser-en-sí, ahumano o suprahumano. Es el supuesto de que tal ontología es imposible o sin sentido lo que hoy debemos cuestionar y superar.

\section{Estética especulativa. Ontología estética.}

Lo que Gadamer deja pronto de lado en su crítica a Kant es el carácter relacional de la experiencia estética, es decir, el que lo bello consista en una relación entre un objeto y un sujeto. Ciertamente Kant se concentró más en el lado subjetivo de esta relación, como Gadamer se concentra más en el lado objetivo (en el ser de lo bello); pero ninguno de los dos se detiene en la relación como tal. Es sobre esto que Steven Shaviro llama la atención: lo bello, nos dice, tiene la forma de un encuentro, de una adaptación o un acoplamiento entre dos seres distintos; "la belleza es, por lo tanto -dice-, un evento, un proceso, más que una condición o un estado. La flor no es hermosa en sí misma; más bien, la belleza sucede cuando encuentro la flor" (Shaviro, 2009: 3). Los seres se acomodan como si estuvieran hechos el uno para el otro. "Como si estuvieran", pues en verdad se trata de una "relación contingente", de un "acaecer" (antes que de un "aparecer"). Este acaecer o "acontecer", este "acontecimiento", plenamente singular, es lo que tiene un carácter "real”, no meramente subjetivo o meramente objetivo. En Kant se halla implícita la idea de que la experiencia de lo bello es un encuentro contingente cuando la caracteriza, a diferencia de la experiencia cognoscitiva o la experiencia moral, como una situación donde el sujeto no legisla, no determina al objeto, sino que simplemente se "dispone" a él -bajo el régimen de un "libre juego de las facultades"-. En términos de Kant, la experiencia estética no 
es un acto o una actividad del sujeto, no es obra del deseo humano -el deseo pertenece al reino de la razón práctica, moral- ni de un interés cognoscitivo que subordina lo dado fenoménico a las estructuras de la subjetividad cognoscente. Pertenece, más bien, desarrolla Shaviro, al orden de la pasión, del pathos: hay necesariamente un elemento pasivo, receptivo en la experiencia de lo bello: el sujeto se dispone a la cosa que se le ofrece (Shaviro, 2009: 6). No hay determinación del sujeto sobre el objeto, ni determinación del objeto sobre el sujeto: la cualidad de lo bello, insiste Kant, no es una cualidad del objeto. Más allá de Kant, tampoco es una cualidad del sujeto. Es, como decimos, una cualidad del encuentro, de la relación.

Shaviro generaliza, usando las filosofías de Whitehead y Deleuze, la noción de lo bello como "encuentro contingente" a la definición misma del Ser. Las relaciones de exterioridad, como se presentan en el encuentro entre la rosa y el sujeto que la contempla, rigen todo el orden de lo existente. Esto es, hay "encuentros", "relaciones" no sólo entre el objeto y el sujeto sino entre las cosas mismas; hay relaciones aunque no haya un sujeto humano que participe en ellas: la rosa también se relaciona con los insectos que la visitan, con otras flores que la acompañan (¿y con las que quizá compite en ser bellas?). Pasamos, pues, al plano ontológico de las relaciones. Y en este plano las relaciones de exterioridad lo son casi todo. La taza de café, el café y el plato están regidas por una relación de exterioridad contingente $-\mathrm{o}$ relativamente contingente, "contingentemente obligatoria", como dice Manuel DeLanda (2016: 3)-, esto es, no existe ninguna conexión intrínseca y necesaria entre los tres objetos, aunque casi siempre vayan juntos. Las relaciones de interioridad serían las que rigen la composición interna de cada uno de esos objetos por separado. La oreja de la taza tiene una relación de interioridad con el resto de la taza. ¿Pero qué son estas relaciones de interioridad? ¿En qué consisten? 
En términos del filósofo norteamericano neorrealista Graham Harman, las relaciones de interioridad constituirían la "sustancia" o el "objeto real" y las relaciones de exterioridad formarían el "objeto sensual" -el "objeto intencional" en términos husserlianos. Creador de la variante "ontología orientada a objetos" del realismo especulativo, Harman propone sustituir la dupla clásica sujeto-objeto por la dupla objeto real-objeto sensual (Harman, 2016: 170192). Todo es objeto. El propio sujeto es un objeto, y las cualidades que el sujeto pone en el objeto en realidad pertenecen al objeto -son las cualidades sensuales del objeto sensual-. ${ }^{3}$ Hay inter-objetualidad: los objetos se relacionan entre sí, son aprehendidos y comprendidos unos por otros, se "encuentran" entre ellos haya o no un sujeto que atestigüe ese encuentro. Harman sostiene que el objeto real, la sustancia, es por principio inaccesible e irreductible; el objeto real se retira sobre sí mismo, "las cosas mismas permanecen para siempre más allá de nuestro alcance" (Harman, 2016: 171), aunque a la vez afirma, más allá del escepticismo kantiano, su indiscutible existencia. Ésta es, para él, la formulación más precisa de una ontología realista. Los objetos y cualidades sensuales mantienen una relación indirecta o "alusiva" con los objetos y las cualidades reales. No hay relación directa entre los objetos reales: cada uno permanece cerrado sobre sí mismo, es una "mónada sin ventanas" a la manera leibniziana. Esto significa que no existen relaciones de causalidad real -eficiente- entre los objetos; dada su autonomía total -autarquía- cada objeto real es impenetrable e intocable de suyo; sólo puede haber, en el nivel de los objetos sensuales, lo que Harman llama "causalidad vicaria", ocasional, expresiva, esto es, estética. En el plano sensual, las cosas se perciben entre sí

${ }^{3}$ Una bella forma de decir esto: "Aspiro el olor de una rosa e inmediatamente me vuelven a la memoria confusos recuerdos infantiles. A decir verdad, estos recuerdos no han sido en absoluto evocados por el aroma de la rosa: los aspiro en el olor mismo; ella es para mí todo eso" (Bergson, 1999: 117). 
y se afectan entre todas. Su relación es metafórica. Ciertamente, para Harman, la metáfora no es un procedimiento meramente lingüístico - un juego de palabras- sino originalmente ontológico: es en el plano de las cualidades sensuales y de los objetos sensuales donde se da la transposición metafórica, poética: "el ciprés es una llama”. El ciprés-llama configura un tercer objeto donde las cualidades separadas del ciprés y de la llama se funden en un objeto singular e inconfundible. La metáfora logra lo que ningún conocimiento y ninguna observación puede hacer: aprehender a través de un objeto sensual enriquecido la esencia misma de un objeto real. En general, Harman propone concebir a la estética como vía privilegiada para la metafísica (Cf. Harman, 2015: 105-124; 2007: 9).

En el pequeño ensayo "La tercera mesa" (Harman, 2017: 225233), el filósofo norteamericano explica la prioridad ontológica de la perspectiva estética. Según su análisis existen tres clases de mesas (de objetos o de maneras de concebir al objeto): 1) la mesa tal como es definida desde nuestra experiencia sensible, fenomenológicamente explicada, esto es, como un conjunto de cualidades subjetivas que otorgan un ser intencional al objeto; no hay aprehensión del ser en sí de la mesa sino sólo de su configuración como correlato de nuestras vivencias; de alguna manera, la mesa es nuestra "obra"; 2) la mesa tal como la concibe el físico, la ciencia, es decir, como un conjunto de partículas atómicas y subatómicas cuya configuración real escapa a nuestra aprehensión y donde sólo las construcciones y fórmulas científicas nos otorgan su verdadero ser; 3) "la tercera mesa", que es la mesa como es en sí misma, en su ser propio, autónomo y silencioso, la mesa que se retrae a toda vivencia o representación -subjetiva u objetiva- y que sólo puede ser constatada más que aprehendida por la experiencia estética. La tercera mesa 
se sitúa justo entre las otras dos, ninguna de las cuales es realmente una mesa. Esta tercera mesa emerge como algo distinto a sus componentes y también se oculta detrás de sus efectos externos. Nuestra mesa es un ser intermedio que no es localizable a partir de la física subatómica ni de la psicología humana, sino que habita una zona permanente y autónoma donde los objetos son simplemente ellos mismos (Harman, 2017: 229).

En general, Harman revive para la estética un principio de ontología negativa (realismo negativo): a través de las percepciones tenemos noticia de una "cosa en sî" - de una sustancia, en términos aristotélicos- que se retira a todo encuentro pero que da razón de las cualidades que captamos de ella. Las cualidades sensibles "aluden" a las cualidades reales, las que a su vez son como "emanaciones" del objeto real. ${ }^{4}$ Para Harman no hay ningún problema. Lo bello y el arte no captan o aprehenden la cosa misma porque el asunto con lo real no es captarlo, aprehenderlo, representarlo o conocerlo sino constatarlo, admirarlo, "amarlo".

La ontología del objeto de Harman y su realismo de la sustancia, ¿es compatible con la ontología de procesos -o nuevo materialismo- a la manera de Shaviro (y otros, como Deleuze, Bruno Latour, Manuel DeLanda, etcétera)?, es decir, ¿son compatibles una perspectiva filosófica que entiende lo real como objeto irreductible y otra que lo entiende como proceso material, dinámico e inventivo? El joven filósofo norteamericano Levi Bryant, mediando entre las filosofías de Graham Harman y Gilles Deleuze, ha propuesto una concepción del objeto harmaniano (el "objeto real”) como una "potencia" o un ser "virtual" que es la "razón" de las cualidades sensuales y las relaciones dinámicas en que participa. La mesa no

${ }^{4}$ Para una exposición sistemática de la teoría harmaniana de los objetos y sus relaciones e interrelaciones, ver Harman (2016b). 
"es" algo, es una potencia, un poder-ser; hay que decir, a la manera de Deleuze, que la mesa "mesea", hace algo siendo lo que es, no es una cosa inerte, cerrada y acabada. El ejemplo de Bryant es una taza: "la azulidad de la taza - explica- no es una cualidad que la taza tiene, sino algo que la taza hace" (Bryant, 2011: 90). La taza azulea, podríamos decir. En suma: "sustancia" o "potencia virtual", el Ser se aparece para el nuevo realismo como lo irreductible, lo irrepresentable, como distancia y exterioridad, como "ser-allá" antes que como "ser-ahí" (Dasein). Este acontecer de la cosa, su ser acontecimiento, su "realidad ejecutante" (Ortega y Gasset) es lo que llamamos "belleza".

Así, llegamos a la pregunta estético-ontológica fundamental: ¿existe la belleza independientemente de quien la contempla? La respuesta que avanzamos es precisamente que, todo lo contrario, experimentar algo como existiendo independientemente de nosotros es la experiencia misma de la belleza. Ver las cosas como si no fuéramos nosotros los que las vemos, verlas como se ven a sí mismas, o entre ellas mismas, allá, solas, autónomas, autosuficientes, calladas, perfectas: esa es la experiencia de la belleza. Sorprender a la "cosa en sî" en su quieta, generosa e infinita intimidad: eso es lo bello. La oportunidad que tenemos siempre y a cada momento de encontrarnos con el ser en tanto que ser.

Para el caso del arte, particularmente para la innovación vanguardista de inicios del siglo xx, cabe recordar y recuperar desde el nuevo realismo, el ensayo del filósofo español José Ortega y Gasset "La deshumanización del arte" (1985). Quizá en su momento este ensayo fue entendido como una crítica del arte del siglo xx, aunque, en verdad, se trata de una caracterización ontológica de un arte que rompe con la función humanista de reproducir y hasta celebrar el reino de lo humano -de ahí su carácter anti-popular y, por ende, impopular-. Según Ortega, ese es un rasgo sólo del arte del siglo XIx; en verdad, afirma, "todas las grandes épocas del arte 
han evitado que la obra tenga en lo humano su centro de gravedad" (Ortega y Gasset, 1985: 20). Más que de deshumanización, que conlleva un sentido meramente negativo, deberíamos hablar simplemente de un arte ahumano o no-humano -y no antihumano o inhumano-. Para Ortega esto es un signo de liberación, de emancipación de la esfera estética de determinaciones "demasiado humanas" y abre, precisamente, hacia una visión de la realidad tal cual, esto es, hacia una concepción ontológica del arte. Aunque el arte anterior -el del siglo XIX- presumía ser "realista", se trata de un realismo acorde con definiciones y prescripciones humanas, socialmente determinadas -es un realismo correlacionista, podemos decir en los términos del realismo especulativo-. Si bien Ortega interpreta al nuevo arte desde una perspectiva anti-realista, ponderando el carácter etéreo, abstracto y libre de los objetos artísticos, esto puede ser reinterpretado desde el nuevo realismo como un arte que cuestionando el realismo antropocéntrico nos abre verdaderamente hacia lo real, hacia la realidad que está más allá de nuestros conceptos y determinaciones.

\section{El principio de "irrazón” como principio estético.}

De acuerdo con la tesis de Anna Longo, la estética del realismo especulativo no sólo se encuentra en el campo del arte -lo que todavía estaría a discusión: ¿cómo sería un arte que sigue los lineamientos de esta filosofía?- sino, ante todo, como una actitud o un rasgo del propio pensamiento especulativo (Longo, 2017). Dice Longo: "más que buscar una estética adaptado al realismo especulativo, se trataría más bien de reconstruir la funcionalidad del componente estético de la especulación" (Longo, 2017: 91; traducción nuestra). De acuerdo con esta afirmación nos interesa dilucidar e interpretar el "principio de irrazón" propuesto por Quentin Meillassoux como el principio estético-ontológico fundamental: un principio que no 
sólo da cuenta del ser estético -lo bello, el arte- sino de todo ente existente y del proceso general de lo real.

En principio, es importante señalar que la ontología de Meillassoux tiene como base primera la tesis de la prioridad del "ente" sobre el "Ser"; la suya es una ontología del ente más que una ontología del Ser. El ente es lo que existe y es, por ende, lo que existe en el tiempo. Nada existe fuera del tiempo o, más bien, existir y ser temporal son lo mismo. Como decía Bergson, el tiempo es la tela de que está hecho lo real. ${ }^{5}$ Es por el tiempo que existe algo y no más bien nada. Esto implica también una profunda y radical filosofía de la inmanencia. El ente, lo existente, se basta a sí mismo, no tiene una causa fuera de sí; por esto, no hay ninguna "necesidad" en el orden de la existencia: no hay ninguna razón o causa última por la cual una cosa es lo que es. Todo ente puede ser o puede no ser, puede ser esto o puede ser lo otro. Ésta es la fórmula del carácter absoluto de la contingencia como principio de todo lo existente. Así, contra el "principio de razón" -nada hay sin razón- estatuido por la tradición metafísica, Meillassoux propone lo que llama el "principio de irrazón” -de no-razón-, es decir, según sus palabras, "la ausencia última de razón -lo que denominamos la irrazón- es una propiedad ontológica absoluta y no la marca de la finitud de nuestro saber" (Meillassoux, 2015: 91). La sin-razón está del lado del Ser mismo; el principio de razón es falso, absolutamente falso, incluso, precisa Meillassoux. "Porque nada, en verdad, tiene razón de ser y de seguir siendo así más que de otra manera, ni las leyes del mundo, ni las cosas del mundo. Todo puede realmente colapsar, tanto los árboles como los astros, los astros como las leyes, tanto las leyes físicas como las leyes lógicas. Y no en virtud de una ley superior que destinaría toda cosa a su pérdida, sino en virtud de

\footnotetext{
5 "El tiempo es lo que se hace y lo que hace que todo se haga" (Bergson, 1972).
} 
la ausencia de una ley superior capaz de preservar de su pérdida a cualquier cosa de la que se trate" (Meillassoux, 2015: 91-92). ${ }^{6}$

El principio de irrazón declara una verdad que todos de alguna manera hemos constatado pero que normalmente y con todos los medios nos negamos a reconocer: que no hay ninguna razón por la cual existimos y existe todo lo existente. Que no hay de suyo un sentido en el Ser y ni siquiera cabe, por el mismo principio de contingencia, el consuelo de que nosotros vamos a "poner" ese sentido -como rezaba el existencialismo sartriano. El ser humano es tan contingente como cualquier ente. Contra estas verdades, efectivamente metafísicas y absolutas, se ha rebelado todo el pensamiento de la tradición, toda metafísica de la necesidad, dogmática y esencialmente antropocéntrica. Metafísico había sido hasta ahora el pensamiento que busca someter al Ser a la necesidad humana. La nueva metafísica del realismo especulativo plantea todo lo contrario: someter el pensamiento a la contingencia de la existencia. Ahora bien, el pensamiento que, por excelencia y desde siempre, se ha atenido a lo que "hay", que no pide ninguna otra razón de la cosa (de la "rosa", por ejemplo), más que el propio ser de la cosa en su pura contingencia, es el pensamiento estético. Ser capaz de aceptar lo que es tal como es, el ser en cuanto tal, y además celebrarlo regocijadamente, es el pensamiento que todo arte y toda experiencia estética conlleva y afirma -es la proposición fundamental del "espíritu trágico", según Nietzsche-.

Este carácter de sin-razón o de irrazón del objeto estético ya ha sido pensado por la tradición filosófica bajo las ideas de desinterés,

${ }^{6}$ Aunque Heidegger adelanta la crítica al principio de razón lo hace en la perspectiva de cuestionar la metafísica de la representación y bajo la idea de identificar Ser y Razón (“nada es sin razón” puede leerse como el ser es la razón misma). Meillassoux endereza su crítica al principio de razón desde un punto de vista ontológico, cosmológico incluso: no existe una razón alguna ni el Ser es su propia razón porque efectivamente todo ser puede ser destruido sin ninguna razón. 
ser sin fin, inutilidad o "finalidad sin fin" -autotelia-. Esta última es la expresión que usa Kant en el tercer momento de la analítica de lo bello para caracterizar el juicio del gusto (Kant, 2007: 133 y ss.). Más allá de la jerga kantiana, finalidad sin fin designa el carácter formal u orgánico de lo bello - “finalidad”-, esto es, el que el objeto forme una unidad no dirigida por ninguna condición externa al propio objeto, ni el encanto o emoción subjetiva -fin interno- ni la perfección objetiva -fin externo-. "Finalidad sin fin" también puede entenderse como lo que contiene en sí mismo su fin, o lo que es un "fin intrínseco" - un fin absoluto, que no puede ser "medio" para ninguna otra cosa. Este carácter define a lo bello, pero también, en el propio Kant, a lo "bueno", lo "moral", particularmente en términos de la tercera formulación del imperativo categórico, referida a no tratar a las personas como medios para un fin -principio del "respeto"- sino como fines en sí mismos (Kant, 1946: 84). Sin embargo, como ya señaló alguna vez Hannah Arendt, esta concepción es restrictiva, limitativa. Si bien necesaria en principio, termina justificando el mero antropocentrismo $y$, por ende, la desvaloración de lo no humano, la instrumentalización y cosificación general de todo lo existente. ${ }^{7}$ La solución a esta inaceptable consecuencia consistiría precisamente, yendo más allá del antropocentrismo moral kantiano, en extender ontológicamente el principio de la finalidad sin fin: todo lo que existe, la existencia misma, es una finalidad sin fin, es un fin intrínseco, esto es, tiene la forma de un fenómeno o un ser estético. Lo bello es lo ontológicamente primero. Consideramos, así, que es en una ontología estética y no en un antropocentrismo acrítico, donde se fun-

${ }^{7}$ Dice Arendt: "el utilitarismo antropocéntrico del homo faber ha encontrado su mayor expresión en la fórmula kantiana de que ningún hombre debe convertirse en medio de un fin, que todo ser humano es un fin en sí mismo" (Arendt, 1993: 174), de lo que se sigue que todo lo no-humano puede ser instrumentalizado, la Tierra entera puede ser puesta al servicio del humano. 
damentaría realmente el imperativo categórico y toda nuestra concepción del mundo moral, político y cultural. Queda un humano que ya no es el rey de la creación pero que, no obstante, guarda la dignidad superior de ser alguien capaz, nietzscheanamente dicho, de superarse a sí mismo y de abrirse a una trascendencia que no es más que la de la cosa misma, en su esplendor estético primigenio. ${ }^{8}$

\section{¿Un arte especulativo? Hacia una estética ontológica}

Varias cuestiones se abren al pensar de las relaciones entre el realismo especulativo y la práctica artística en sus distintas modalidades. Planteamos nuevamente la pregunta: ¿en qué consistiría un arte conforme con el realismo especulativo? Podemos mencionar varias opciones:

a) Recordar, como dice Ortega y Gasset, que la mayor parte del arte en la historia de la humanidad ha estado fuera de la órbita humanista del arte europeo: el arte oriental -el "arte simbólico" según la tipología de Hegel-, el arte islámico, el nórdico, el precolombino, etc. El filósofo mexicano José Vasconcelos ponderaba la superioridad del arte de las antiguas civilizaciones sobre todas las formas del arte "moderno", a las que juzgaba frívolas y sosas, sin "espíritu". ' Una estética ontológica según los lineamientos del realismo especulativo nos ofrecería la posibilidad de una estética planetaria, abierta a la comprensión de las múltiples manifestacio-

8 "El yo, el lugar donde vivimos, es un lugar de ilusión. La bondad está conectada con el intento por ver el no-yo, por ver y responder al mundo real a la luz de una conciencia virtuosa. Este es el significado no metafísico de la idea de trascendencia" (Murdoch, 2001: 95).

${ }^{9}$ Aunque desde una cierta fenomenología espontánea (o naif), el filósofo mexicano José Vasconcelos presenta trazos conceptuales de lo que sería una metafísica estética (Cf. Vasconcelos, 2009). 
nes artísticas del mundo, más allá de un multiculturalismo -posmoderno- meramente condescendiente y ayuno de criterios.

b) Por otra parte, todo el arte contemporáneo -desde el impresionismo hasta nuestros días- puede ser reinterpretado desde una estética especulativa como práctica de exploración de las posibilidades ontológicas del arte, más allá de las interpretaciones y autocomprensiones de los distintos vanguardismos -dadaísmo, surrealismo, expresionismo, abstracción- en términos puramente formalistas y estilísticos, es decir, como una pura búsqueda de medios adecuados a la intención expresiva del artista -subjetivismo estético-. Por el contrario, ya Merleau-Ponty interpretaba el arte de Paul Cézanne como el intento de captar una naturaleza "prehumana". La pintura de Cézanne, dice, "revela el fondo de naturaleza inhumana en que el hombre se instala. Por esto sus personajes son extrańos y como vistos por un ser de otra especie" (MerleauPonty, 1973: 43).

c) El realismo especulativo puede permitirnos una nueva definición del arte, más vinculada a una tarea filosófica de comprensión ontológica que a las funciones meramente antropológicas de expresión y construcción imaginativa remitidas a la tarea de celebración del mundo humano. Ciertamente, si esta definición ontológica ha de tener un carácter universal, debería ser capaz de cubrir toda forma de arte. Así es efectivamente: toda obra de arte de cualquier ámbito espacio-temporal -histórico-cultural- posee esta dimensión ontológica, particularmente en la medida que toda obra es un objeto, posee una realidad de suyo y abre una dimensión de trascendencia, en principio oscura o enigmática a la percepción humana. Por ejemplo, el filósofo español Eugenio Trías se preocupaba por revelar el elemento siniestro presente más o menos discretamente en las obras más luminosas de la tradición (Trías, 1982). Ciertamente, el arte conceptual y diversas fórmulas extremadamente escandalosas del arte reciente -instalaciones, 
performances, intervenciones, arte del cuerpo, arte con animales, arte ambiental, etc. - han planteado la necesidad de una redefinición de lo que es y lo que no es arte. Un rasgo común a estas manifestaciones está planteando la superación de la concepción esteticista del arte, en el sentido de liberar al objeto artístico de un supuestamente imprescindible componente sensible. ${ }^{10}$ Puede considerarse arte lo que simplemente es una instrucción discursiva para hacer o imaginar una obra. Muchos objetos "artísticos" en realidad consisten simplemente en una expresión parcial de un conjunto de significados asociados de manera conjunta, que deben ser captados tomando en cuenta elementos extra-obra, como el contexto de las propuestas, las ideas de los artistas, el juicio de los críticos de arte, etc. Ciertamente, estos procedimientos no hacen del arte exactamente una teoría o una filosofía, pues los elementos discursivos que los acompañan no están sometidos a la lógica de la elaboración teórica; son más bien ideas difusas, intuiciones filosóficas o enigmas y retos intelectuales y emocionales planteados al espectador. No obstante, la disolución del objeto artístico en ciertas prácticas del arte contemporáneo no elimina una serie de actos y experiencias que pueden seguir siendo consideradas "estéticas": emociones, sensaciones, shocks, actos de imaginación y fantaseo, reflexiones vagas, ludismo.

Una nueva definición del arte o, más bien, una nueva práctica del arte, no puede eliminar de forma total los elementos estéticos-sensibles-, aunque sí eleva exponencialmente la participación de las funciones reflexivas e intelectuales en la actividad artística. $\mathrm{El}$ arte no puede seguir siendo concebido solamente en términos puramente estéticos, sensoriales -algo que ya sostenía Duchamp-.

${ }^{10}$ Ya Marcel Duchamp, delineador en muchos sentidos del arte del siglo xx y del xxi, quería hacer del arte un acto de la inteligencia y no sólo de la sensación (Cf. Duchamp, 1978). 
No se convierte en una actividad filosófica, ciertamente, pero en el arte contemporáneo -incluso o sobre todo en el cine-, cada vez gana más la incorporación directa de elementos filosóficos (en directores como Tarkovsky, Lars von Trier, Iñarritu). La filosofía se ha convertido para algunos artistas contemporáneos en un componente imprescindible para la construcción de obras con mayor profundidad de sentido, con mayor "contenido", rebasando las fórmulas y temáticas consabidas (sobredeterminadas por la narrativa, el formalismo estético o por codificaciones ideológicas, psicológicas o sociológicas).

En suma, el arte actual se puede definir como un medio de exploración-revelación de lo real, como un proceso de paulatina apropiación de dimensiones de lo real tradicional y humanamente expurgadas de la aprehensión y la comprensión, tales como objetos insignificantes, temas oscuros como la muerte, el suicidio, las patologías, el cadáver, la animalidad, lo monstruoso, lo asqueroso; temas novedosos como las posibilidades de la inteligencia artificial, el internet, etc. Todas estas búsquedas se pueden interpretar como el alineamiento del arte en la tarea, filosófica por excelencia, de ampliar considerablemente nuestra comprensión ontológica. En este sentido, el arte se revela cada vez más como el aliado mayor del pensamiento filosófico, a la altura o más arriba de otros aliados tradicionales como la religión, la ciencia o la política. Estamos, así, ante la posibilidad del surgimiento y consolidación de lo que Harman llama la "tercera cultura", más allá de la cultura científica y de la cultura humanista, la cultura de un arte filosófico, ontológico incluso, y de una filosofía estéticamente fundada y orientada. Habría que pensar todavía en cuáles son las tareas e implicaciones en todos los niveles de esa tercera cultura:

Durante siglos, la filosofía ha aspirado a las condiciones de una ciencia rigurosa, aunando fuerzas con las matemáticas o la psi- 
cología descriptiva. Pero, ¿qué pasaría si el contraproyecto de los próximos siglos transformara a la filosofía en un arte? El resultado sería una "filosofía como arte vigoroso" en vez de la "filosofía como ciencia rigurosa" propuesta por Husserl. $\mathrm{Al}$ ser reconvertida de ciencia en arte, la filosofía recuperaría su carácter original en cuanto Eros. En cierto sentido, este modelo erótico es la aspiración básica de la filosofía orientada a objetos: es la única manera, en el clima filosófico actual, de ser justos con el amor al saber que jamás pretendió ser saber a secas (Harman, 2017: 232-233).

\section{Bibliografía}

Arendt, Hannah, 1993, La condición humana, Paidós Barcelona.

Bergson, Henri, 1999, Ensayos sobre los datos inmediatos de la conciencia, Sígueme, Salamanca.

Bergson, Henri, 1972, El pensamiento y lo moviente, La Pléyade, Buenos Aires.

Bryant, Levi R., 2011, The democracy objects, University of Michigan Library, Ann Arbor.

Cassirer, Ernst, 1972, Filosofía de la ilustración, FCE, México.

DeLanda, Manuel, 2016, Assamblage Theory, Edinburgh University Press, Edinburgh.

Duchamp, Marcel 1978, Duchamp du signe, Barcelona, Gustavo Gili.

Gadamer, Hans-Georg, 1977, Verdad y método. Fundamentos de una hermenéutica filosófica, Sígueme, Salamanca.

Harman, Graham, 2016, El objeto cuádruple, Anhtropos, Barcelona. 
, 2017, "La tercera mesa”, Devenires, vol. XVIII, núm. 36, pp. 225-233.

Heidegger, Martin, 1958, Arte y poesía, Samuel Ramos (trad.), FCE, México.

Kant, Immanuel, 2007, Crítica del juicio, Tecnos, Madrid.

Longo, Anna, 2017, "Une esthétique spéculative est elle posible?", Cahiers Critiques de Philosophie, núm. 19.

Meillassoux, Quentin, 2015, Después de la finitud. Ensayo sobre la necesidad de la contingencia, Margarita Martínez (trad.), Caja Negra, Buenos Aires.

Merleau-Ponty, Maurice, 1973, “La duda de Cézanne”, en Sentido y sinsentido, Península, Barcelona.

Murdoch, Iris, 2001, La soberanía del bien, Caparrós, Madrid.

Ortega y Gasset, José, 1985, La deshumanización del arte, Planeta/ De Agostini, Barcelona.

Ramírez, Mario Teodoro (coord.), 2016, El nuevo realismo. La filosofía del siglo XXI, Siglo XXI, México.

Shaviro, Steven, 2009, Without criteria. Kant, Whitehead, Deleuze and Aesthetics, The MIT Press, Massachusetts.

Trías, Eugenio, 1982, Lo bello y lo siniestro, Seix-Barral, Barcelona.

Vasconcelos, José, 2009, Filosofía Estética, Trillas, México. 